\title{
Antimicrobial Effects of $\mathrm{Ag}$ and $\mathrm{ZnO}$ Nanoparticles
}

\author{
M. I. El Gohary, T. I. Shalaby" and S.Y. Megahed \\ Biophysics Branch, Physics Department, Faculty of Science, \\ Al-Azhar University, Cairo and *Biomedical Physics Department, \\ Medical Research Institute, Alexandria University, Alexandria, \\ Egypt.
}

\begin{abstract}
JanOtECHNOLOGY has emerged in the past decades with different disciplines including medicine that plays an important role in improvement of human health. Utilization of nanomaterials in antimicrobial application may help to avoid drawbacks of antibiotics or help to improve their antimicrobial effect against resistance of microorganisms. In the present work, silver $(\mathrm{Ag})$ and zinc oxide ( $\mathrm{ZnO})$ nanoparticles (NPs) are synthesized and characterized using UV-Vis spectroscopy, transmission electron microscope (TEM), XRay diffraction (XRD), and Fourier-transform infrared spectroscopy (FT-IR). The antimicrobial activities of the synthesized $\mathrm{ZnO}$ and $\mathrm{Ag}$ NPs are carried out by the well diffusion and a microtiter methods against different pathogens (Fungi, Gram-positive and Gram-negative bacteria) to reveal their minimum inhibitory concentration (MIC) and the half-maximal inhibitory concentration $\left(\mathrm{IC}_{50}\right)$. The obtained results indicate that both types of nanoparticles are bacteriostatic and bactericidal while silver is more potent than $\mathrm{ZnO}$ NPs.
\end{abstract}

Keywords: Nanotechnology, Ag, ZnO, NPs, Minimum inhibitory concentration (MIC), Half-maximal inhibitory concentration (IC50).

Nanotechnology, the deliberate manipulation of matter at size scales of less than 100 $\mathrm{nm}$, holds the promise of creating new materials and devices that take advantage of unique phenomena realized at those dimensions, because of their high reactivity due to the large surface area to volume ratio. The Nanoparticles possess extraordinary physicochemical, optical and biological properties which can be manipulated suitably for desired applications ${ }^{(1)}$. Nanosized inorganic particles, of either simple or composite nature, display unique physical and chemical properties and represent an increasingly important material in the development of novel nanodevices which can be used in numerous physical, biological, biomedical, and pharmaceutical applications $^{(2)}$.

Silver is a safe and effective anti-bactericidal metal because it is non-toxic to animal cells and highly toxic to bacteria such as Escherchia coli (E. coli) and Staphylococcus aureas ${ }^{(3)}$. Nano-silver in the form of powder as well as suspension have been used as anti-bacterial agents because they enables the loading of small quantities of silver and thus makes the product cost effective. 
Zinc oxide is non-toxic to human beings and noxious to microorganisms. Moreover, zinc is a mineral element necessary to human health and $\mathrm{ZnO}$ is a form in the daily supplement for zinc. $\mathrm{ZnO}$ nanoparticles also have good biocompatibility to human cells ${ }^{(4)}$. $\mathrm{ZnO}$ nanoparticles could be used in various materials and products, including medicine, cosmetics, solar cells, rubber, concrete and also foods ${ }^{(5)}$. Zinc oxide nanoparticles may exhibit stronger antibacterial activity than zinc oxide material itself ${ }^{(6)}$. $\mathrm{ZnO}$ nanoparticles show a significant Antibacterial effects under normal laboratory lighting conditions than other metal oxides nanoparticles ${ }^{(7,8)}$.

In present study, $\mathrm{Ag}$ and $\mathrm{ZnO}$ nanoparticles are prepared using chemical methods. The antibacterial activities of Ag NPs and ZnO NPs are also examined to show their effects upon different microorganisms.

\section{Materials and Methods}

\section{Preparation of Ag nanoparticles}

The silver colloid is prepared by using chemical reduction method according to the description of Fang et al. ${ }^{(9)}$. All solutions of reacting materials are prepared in bi-distilled water. In typical procedure, $50 \mathrm{ml}$ of $1 \mathrm{mM} \mathrm{AgNO}_{3}$ is heated to boiling. To this solution, 5 $\mathrm{ml}$ of $1 \%$ trisodium citrate is added drop by drop. During this process solutions are mixed vigorously. Resulting solution is heated until its color (colorless) change (pale yellow) is evident. Then the solution is removed from the heating element until becomes cool to room temperature.

\section{Preparation of $\mathrm{ZnO}$ nanoparticles}

Chemical reduction method is used for preparation of $\mathrm{ZnO}$ nanoparticles. In a typical procedure zinc nitrate solution $(0.1 \mathrm{M})$ is prepared and kept in magnetic stirrer for continuous stirring to dissolve zinc nitrate completely. Then $0.2 \mathrm{M}$ of sodium hydroxide is added drop wise to the vessel and mixed well using magnetic stirrer, withstand the mixture in stirrer for $2 \mathrm{hr}$, then the solution is incubated at room temperature for $24 \mathrm{hr}$ for settlement, the settled white precipitate is centrifuged at $10,000 \mathrm{rpm}$ for $10 \mathrm{~min}$. The supernatant is discarded and the pellets are washed several times with distilled water to remove byproducts. After washing the nanoparticles by bi-distilled water and ethanol, they dried at $300{ }^{\circ} \mathrm{C}$ in hot air oven for $2 \mathrm{hr}$. During drying process, zinc hydroxide is completely converted into zinc Oxide. ${ }^{(4)}$

\section{Characterization of nanoparticles}

The optical properties (absorbance) of colloidal solutions of both $\mathrm{ZnO}$ and $\mathrm{Ag}$ nanoparticles are evaluated by UV/VIS spectrophotometer (Jenway 6500, UK) at wavelength range: 200-900 nm. Size and morphology of the prepared NPs are studied using transmission electron microscope (JEOL-100 CX). The crystalline nature of the prepared nanoparticles is examined using powder X-ray diffractometer (XPERT-PROPANalytical-Netherland) using CuK $\alpha$ target radiation at $45 \mathrm{kV}$ in the range of 10-80 (20). The crystalline dimension is calculated using Scherrer equation:

$$
D=\frac{0.9 \lambda}{\beta \cos \theta}
$$

Egypt. J. Biophys. Biomed. Engng. Vol. 17(2016) 
where $\lambda$ is the wavelength of $X$-ray radiation and $\beta$ is the full width at half maximum of the peaks at diffracting angle $\theta$. The Fourier transform infrared spectroscopy analysis (Shimazdu Prestige-21) is performed to identify the possible functional groups involved in the synthesis of the nanomaterials. The samples are mixed with $\mathrm{KBr}$ and then pressed into thin pellets. Infrared spectra are measured at wavenumber range from 400 to $4000 \mathrm{~cm}^{-1}$.

\section{Determination of antimicrobial activity}

The antimicrobial susceptibility of $\mathrm{Ag}$ and $\mathrm{ZnO}$ nanoparticles is evaluated using the well diffusion and the microtiter method to determine the minimum inhibitory concentration (MIC). For well diffusion technique, a well of diameter $6.0 \mathrm{~mm}$ performed in the agar plate of the microorganisms and $100 \mu \mathrm{l}$ of nanoparticles are added into the well. The cultured agar plates are incubated at $37^{\circ} \mathrm{C}$ for $24 \mathrm{hr}$. After $24 \mathrm{hr}$ of incubation, the zone of inhibition is measured.

For determination of MIC, different concentrations of the $\mathrm{ZnO}$ NPs (from 0.49 to $125 \mu \mathrm{g} / \mathrm{ml}$ ) and of Ag NPs (from 0.06 to $15.63 \mu \mathrm{g} / \mathrm{ml}$ ) are used. Microbial suspension at concentration $5 \times 10^{5} \mathrm{CFU} / \mathrm{ml}$ in sterile 96 -well flatbottomed microtiter plate is used. To each well $100 \mu$ l of the desired NPs concentration added (three wells for each microorganism) against three wells contain microorganism without addition of the nanoparticles. Plates of both type of bacteria (Gram-positive and Gram-Negative bacteria) incubated for $24 \mathrm{hr}$ at $37^{\circ} \mathrm{C}$ and plates of fungi (Aspergillus fumigates and Candida albicans) incubated for $48 \mathrm{hr}$ at $28^{\circ} \mathrm{C}$. The optical density of all suspensions are measured using a multi-detection microplate reader (Sun Rise- Tecan, USA) at $600 \mathrm{~nm}$. The percentage of growth at each concentration of nanoparticles is calculated with the following equation:

Growth $\%=\left[\left(\mathrm{OD}_{600}\right.\right.$ of wells containing the sample/ $\mathrm{OD}_{600}$ of the samplefree well) $\mathrm{x} 100]^{(10)}$.

\section{Results and Discussion}

Figure 1 shows the XRD pattern of the as prepared $\mathrm{Ag}$ and $\mathrm{ZnO}$ nanoparticles. Nine prominent peaks for $\mathrm{ZnO}$ observed at $2 \theta$ angle $\left(31.74^{\circ}\right.$, $\left.34.42^{\circ}, 36.24^{\circ}, 47.5^{\circ}, 56.62^{\circ}, 62.83^{\circ}, 66.4^{\circ}, 67.93^{\circ}, 69.05^{\circ}\right)$. All peaks are the characteristics peaks of ZnO NPs according to (JCPDS-79 0206) without other extra strange peaks detected which indicate to the phase purity ${ }^{(11,12)}$. Average crystallite dimensions is determined by the well-known sherrer's equation (eq: 1) from the full width at half maximum of the most intense peak that are found to be $22 \mathrm{~nm}$.

XRD pattern of Ag NPs shows that, all diffraction peaks correspond to the characteristic face centered cubic (FCC) silver lines. These four peaks are observed at $2 \theta$ angle $\left(38.07^{\circ}, 44.18^{\circ}, 64.37^{\circ}, 77.29^{\circ}\right)$, have been indexed as (111), (200), (220) and (311), respectively. The average crystallite dimension for $\mathrm{Ag}$ as determined by Scherer's formula are found to be $10 \mathrm{~nm}$. 


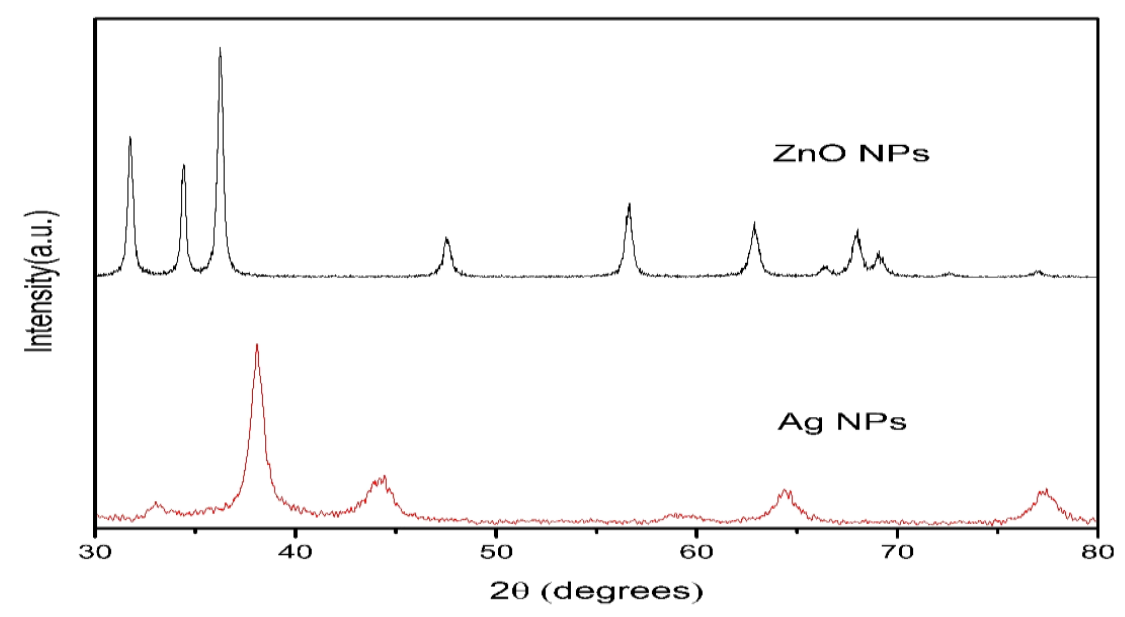

Fig. 1 .XRD patterns of $\mathrm{Ag}$ and $\mathrm{ZnO}$ nanoparticles.

The TEM images are shown in Fig. 2 and 3 that illustrate the TEM images of both $\mathrm{Ag}$ and $\mathrm{ZnO}$ nanoparticles, respectively. TEM investigation of Ag NPs shown that particles shape is more like nanospheres and show homogeneous distribution of the nanoparticles and less aggregation. Particles dimensions obtained from TEM image of Ag NPs are agreed with that obtained from XRD data to be around $10 \mathrm{~nm}$. Figure 3 shows the TEM of ZnO NPs that appear as rod-like shape. Dimensions of $\mathrm{ZnO}$ NPs are close to that obtained by XRD data.

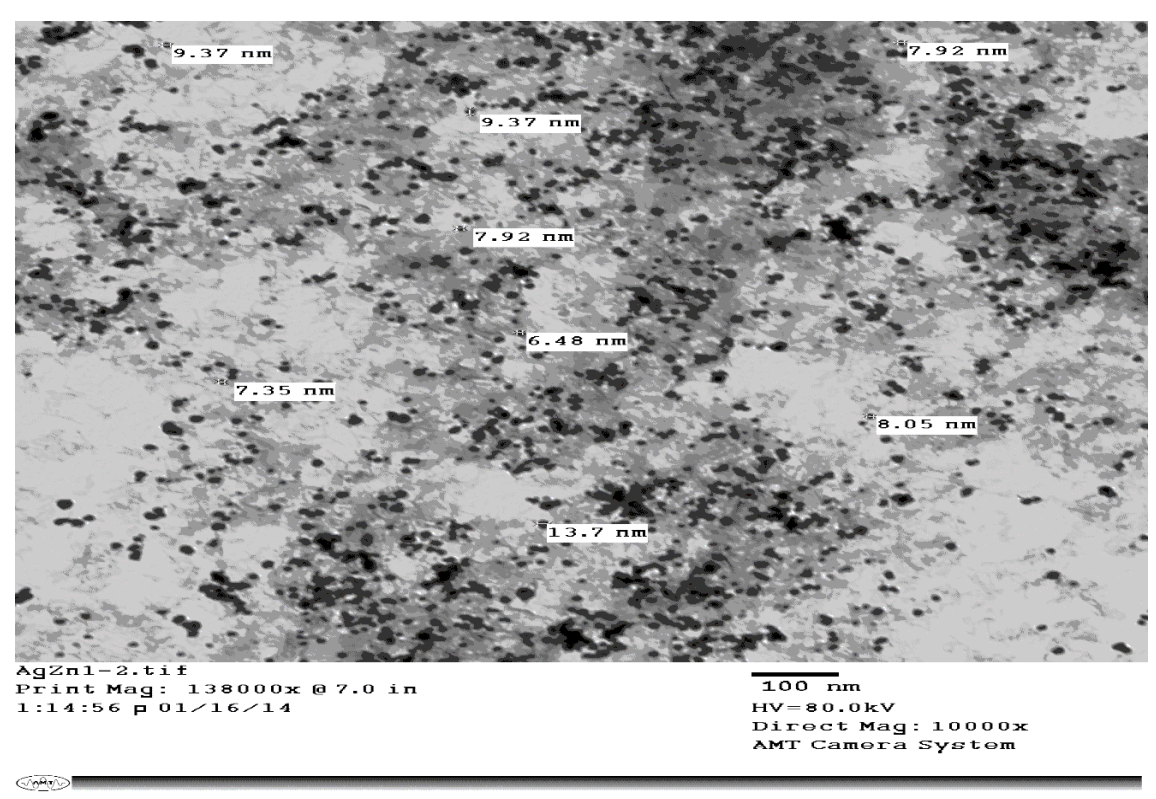

Fig. 2 .TEM image of Ag nanoparticles.

Egypt. J. Biophys. Biomed. Engng. Vol. 17(2016) 


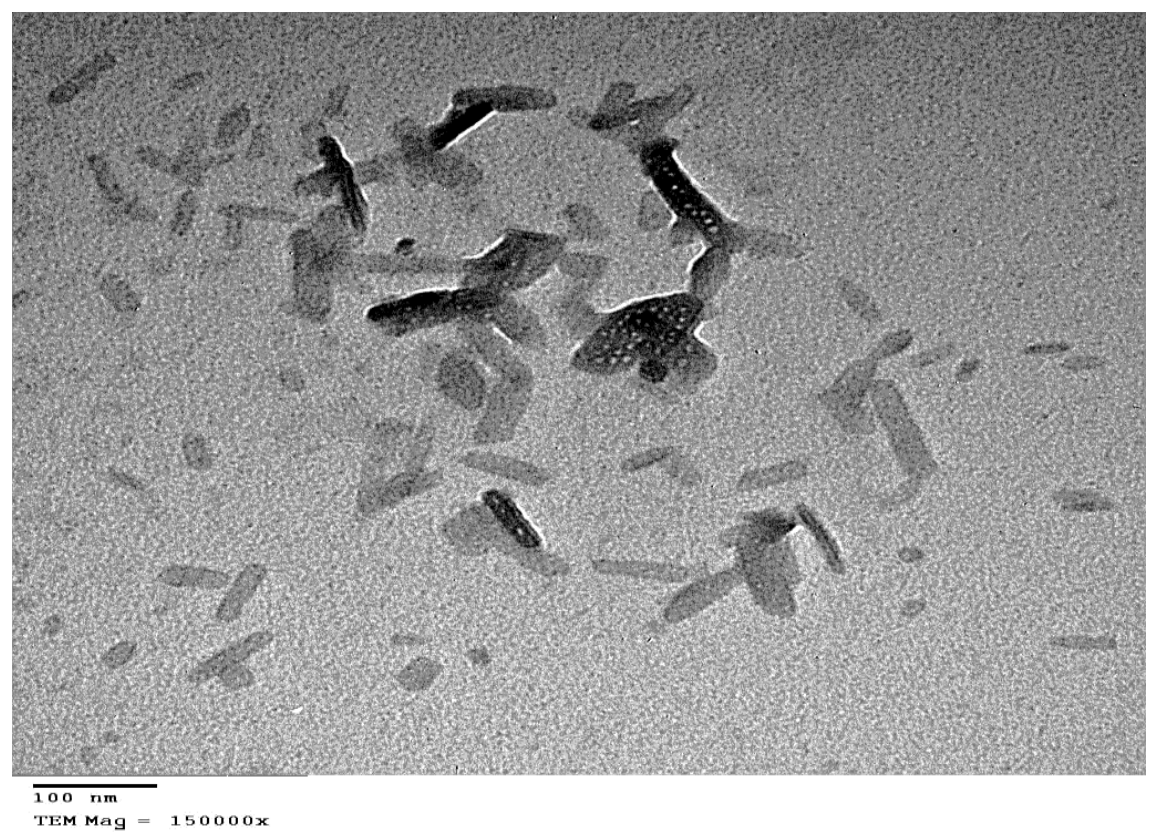

Fig. 3. TEM image of $\mathrm{ZnO}$ nanoparticles.

The UV-Vis spectra of the prepared $\mathrm{Ag}$ and $\mathrm{ZnO}$ nanoparticles are shown in Fig. 4. The maximum absorption band located at $375 \mathrm{~nm}$ for $\mathrm{ZnO}$ NPs, which confirms the property of $\mathrm{ZnO}$ as UV-filter ${ }^{(13)}$. The optical absorption spectra of metal nanoparticles are dominated by surface plasmon resonance (SPR), which shift to longer wavelengths with increasing particle size ${ }^{(14)}$. The number of SPR peaks increases as the symmetry of the nanoparticles decreases, hence different shaped nanoparticles of silver may show one, two or more peaks ${ }^{(15)}$. The absorption spectrum of $\mathrm{Ag}$ nanoparticles (nanosphere) prepared by reduction method shows a sharp SPR feature at $425 \mathrm{~nm}$ indicating monodispersity of the sample without any anisotropic features that agree with TEM investigation ${ }^{(16)}$. Absorption spectrum of $\mathrm{Ag}$ nanoparticles formed in the reaction media has absorbance maxima at $425 \mathrm{~nm}$, which is characteristic for $\mathrm{Ag} \mathrm{NPs}{ }^{(2)}$.

FT-IR spectra of both $\mathrm{Ag}$ and $\mathrm{ZnO}$ nanoparticles are shown in Fig. 5. In the FT-IR spectra, the band at $540 \mathrm{~cm}^{-1}$ in $\mathrm{ZnO}$ spectrum is attributed to vibration of $\mathrm{Zn}-\mathrm{O}$ bond. The bands appeared at 900 and $1380 \mathrm{~cm}^{-1}$ in $\mathrm{ZnO}$ spectrum are assigned to $\mathrm{C}-\mathrm{O}$ stretching mode in carbonate group of residual organic compound (ethanol) from washing procedure. Two bands located at 1668 and $3398 \mathrm{~cm}^{-1}$ in both $\mathrm{ZnO}$ and $\mathrm{Ag}$ spectra are assigned to deformation mode of $\mathrm{O}-$ $\mathrm{H}$ attributed to the absorbed water molecules. In $\mathrm{Ag}$ spectrum, the band observed at $2088 \mathrm{~cm}^{-1}$ is attributed to citrate precursor $-\left(\mathrm{CH}_{2}\right)^{(17,18)}$. 


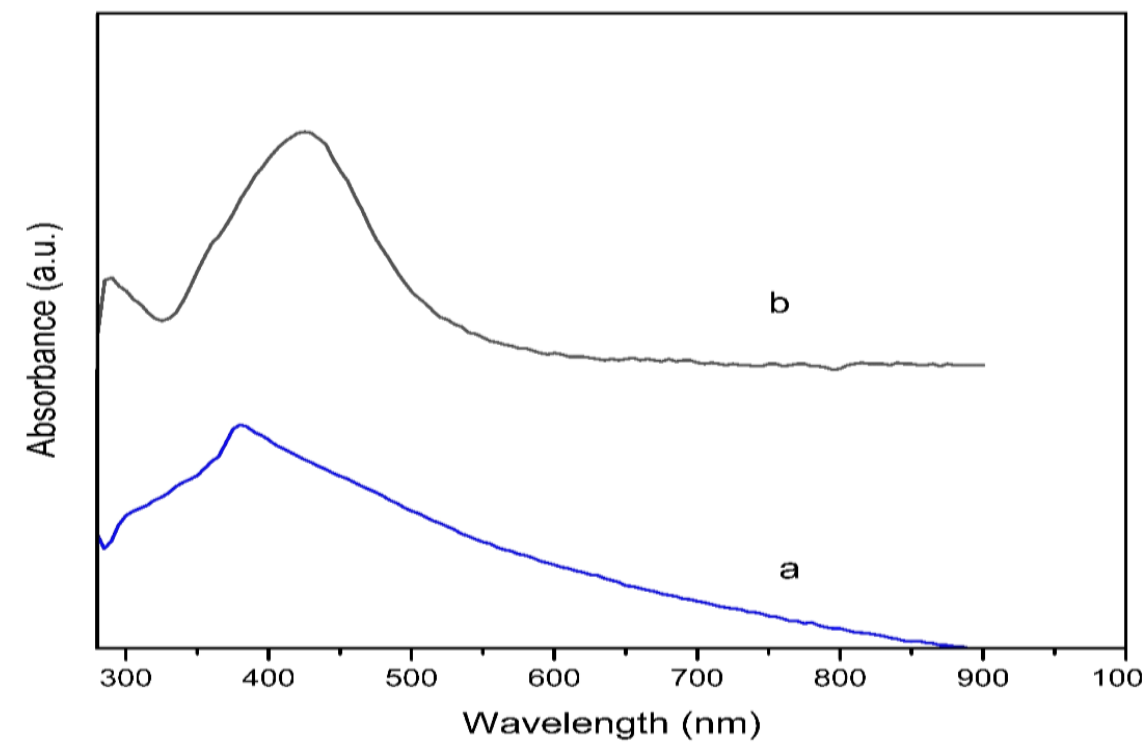

Fig. 4. UV-Vis spectra of $\mathrm{ZnO}$ nanoparticles (a) and Ag nanoparticles (b).

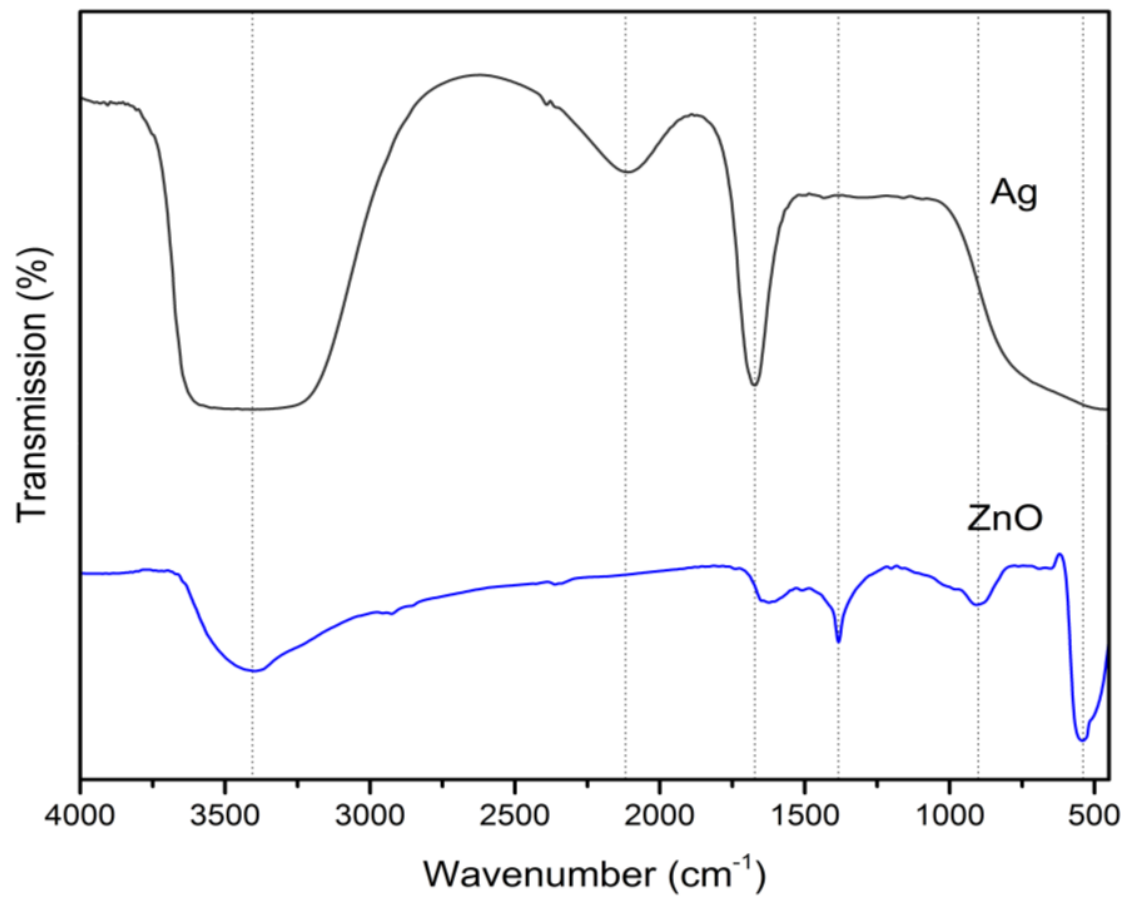

Fig. 5. FT-IR spectra of $\mathrm{Ag}$ and $\mathrm{ZnO}$ nanoparticles.

Egypt. J. Biophys. Biomed. Engng. Vol. 17(2016) 
Antimicrobial activity

$\mathrm{ZnO}$ and $\mathrm{Ag}$ nanoparticles antimicrobial activity are studied against different pathogenic microorganisms (Fungi, Gram positive and Gram negative bacteria). These nanoparticles are dispersed in water bath sonication. Aqueous dispersion of $\mathrm{ZnO}$ and $\mathrm{Ag}$ nanoparticles of desired concentration was made.

\section{Well diffusion results}

The antimicrobial effects of $\mathrm{ZnO}$ and $\mathrm{Ag}$ nanoparticles on different microorganisms are performed. Table 1 summarized the mean diameter \pm standard deviation of the clear inhibition zones around the well treated with Ag and $\mathrm{ZnO}$ NPs. it is clear that, both types of NPs have antimicrobial effect but Ag NPs is more potent than $\mathrm{ZnO}$ NPs.

TABLE 1. Mean zone of inhibition in $\mathrm{mm} \pm \mathrm{SD}$ of $\mathrm{Ag}$ and $\mathrm{ZnO}$ nanoparticles against different Microorganisms. (NA=Not available).

\begin{tabular}{|c|c|c|}
\hline Microorganisms & ZnO NPs & Ag NPs \\
\hline \multicolumn{3}{|c|}{ Fungi } \\
\hline $\begin{array}{l}\text { Aspergillus fumigates } \\
\text { (RCMB 02569) }\end{array}$ & $17.2 \pm 0.58$ & $18.3 \pm 0.25$ \\
\hline $\begin{array}{l}\text { Candida albicans } \\
\text { (RCMB 05038) }\end{array}$ & NA & NA \\
\hline \multicolumn{3}{|c|}{ Gram-Positive Bacteria } \\
\hline $\begin{array}{l}\text { Streptococcus pneumonia } \\
\text { (RCMB 010015) }\end{array}$ & $20.6 \pm 0.15$ & $20.8 \pm 0.43$ \\
\hline $\begin{array}{l}\text { Bacillis subtilis } \\
\text { (RCMB 010069) }\end{array}$ & $21.2 \pm 0.42$ & $22.3 \pm 0.53$ \\
\hline \multicolumn{3}{|c|}{ Gram-Negative Bacteria } \\
\hline $\begin{array}{l}\text { Pseudomonas aeruginosa } \\
\text { (RCMB 010048) }\end{array}$ & NA & NA \\
\hline $\begin{array}{l}\text { Escherichia coli } \\
\text { (RCMB 010059) }\end{array}$ & $17.4 \pm 0.53$ & $19.6 \pm 0.25$ \\
\hline
\end{tabular}

\section{Micro-titer results}

The antimicrobial activity of $\mathrm{Ag}$ and $\mathrm{ZnO}$ nanoparticles is detected by microtiter method to reveal their minimum inhibitory concentration (MIC) and the half maximal inhibitory concentration $\left(\mathrm{IC}_{50}\right)$. The $\mathrm{MIC}$ is determined as the lowest concentration that inhibited the visible growth of microorganism. Table 2 summarizes the MIC of the tested $\mathrm{Ag}$ and $\mathrm{ZnO}$ NPs samples against different types of microorganisms. The present results reveal that the antimicrobial activity of Ag NPs are more effective than ZnO NPs, these data confirm the 
results obtained by well diffusion method. Inhibiting activity of these nanoparticles against Aspergillus fumigates, Streptococcus pneumonia, Bacillis subtilis and Escherichia coli show an agreement with the results obtained by the authors ${ }^{(4,9,20-25)}$. Results of resistance appeared against some microorganisms, e.g. C. abicans and $P$. aeruginosa are different with the results obtained by Yousef \& Daniel ${ }^{(19)}$ and Shailaja et al. (22). This may be due to lower concentration used in the present study, it is reported that MIC for $C$. abicans is $100 \mu \mathrm{g} / \mathrm{ml}^{(26)}$.

Higher activity of Ag nanoparticles may be attributed due to their small size and their higher surface-to-volume ratio. This helps to increase penetration of nanomaterials through membrane of microorganism and increase the chemical interaction activity of the nanomaterial in the microorganisms environment ${ }^{(25)}$.

Mechanisms of interaction of nanomaterials with the microorganisms still not fully understood ${ }^{(20)}$. There are many mechanisms of antimicrobial activity of $\mathrm{Ag}$ and $\mathrm{ZnO}$ NPs that may be summarized as follow: ZnO NPs may adhere with cell wall and interact with building elements that causing destruction of $i^{(19)}$. On entrance into microorganism $\mathrm{ZnO}$ reacts with proteins and DNA results in denaturation them ${ }^{(22)}$. Releasing of $\mathrm{Zn}^{+2}$ ions that cause deformation or swelling of membrane ${ }^{(27)}$. $\mathrm{ZnO}$ plays role in generation of reactive oxygen species $(\mathrm{ROS})^{(20)}$. Also mechanisms of interaction of Ag NPs with microorganisms is the same as $\mathrm{ZnO}^{(2,25)}$. Besides, interaction with thiol group $-\mathrm{SH}$ by replacing $\mathrm{H}$ atom to be $(-\mathrm{S} \mathrm{Ag})$ which cause inhibiting growth of microorganism, silver-amino acid interactions, enhancing phosphate efflux and inhibition of uptake ${ }^{(24,28,29)}$.

TABLE 2. MIC and IC50 of both Ag and ZnO NPs against different types of microorganisms.

\begin{tabular}{|l|c|c|c|c|}
\hline \multirow{2}{*}{ Microorganism } & \multicolumn{2}{|c|}{ ZnO NPs } & \multicolumn{2}{c|}{ Ag NPs } \\
\cline { 2 - 5 } & MIC $(\boldsymbol{\mu g} / \mathbf{m l})$ & IC50 $(\boldsymbol{\mu g} / \mathbf{m l})$ & MIC $(\boldsymbol{\mu g} / \mathbf{m l})$ & IC50 $(\boldsymbol{\mu g} / \mathbf{m l})$ \\
\hline A.fumigatus & 31.25 & 88 & 3.9 & 9.92 \\
\hline C.albicans & NA & NA & NA & NA \\
\hline S.pneumoniae & 1.95 & 30.4 & 1.95 & 10.9 \\
\hline B.subtilis & 0.98 & 10.3 & 0.49 & 2.63 \\
\hline P.aeruginosa & NA & NA & NA & NA \\
\hline E.coli & 15.63 & 73.8 & 3.9 & 14 \\
\hline
\end{tabular}

Egypt. J. Biophys. Biomed. Engng. Vol. 17(2016) 


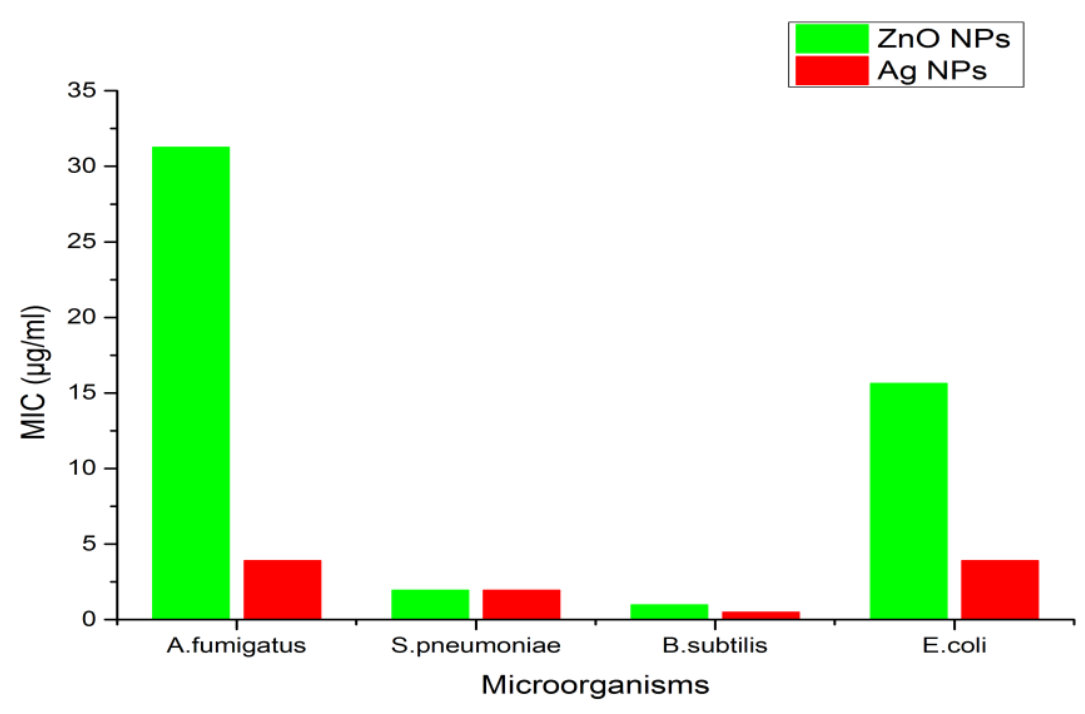

Fig. 6. MIC of Both Ag and ZnO NPs against different types of microorganisms.

\section{Conclusion}

Simple, rapid and inexpensive methods have been developed to prepare $\mathrm{ZnO}$ and Ag nanoparticles. The silver nanoparticles synthesized and analyzed in present study are found to have stronger antimicrobial potency than ZnO NPs.

The MIC of $\mathrm{Ag}$ is lower than that of $\mathrm{ZnO}$ which indicates that $\mathrm{Ag}$ is more potent than $\mathrm{ZnO}$ in agreement with the result obtained by well diffusion desk.

Due to their antimicrobial activity, little toxicity and some properties, it is suggested that $\mathrm{Ag}$ and $\mathrm{ZnO}$ nanoparticles can be used as antimicrobial agents or used in combination with synthetic antibiotics to enhance their antimicrobial activity.

\section{References}

1. Sharma, N., Kumar, J., Thakur, S., Sharma, S. and Shrivastava, V., Antibacterial study of silver doped zinc oxide nanoparticles against Staphylococcus aureus and Bacillus subtilis. Drug Invent. Today, 5, 50-54 (2013).

2. Sondi, I. and Salopek-Sondi, Brnaka, Silver nanoparticles as antimicrobial agent: a case study on E. coli as a model for Gram-negative bacteria. J. Colloid and Interface Sci. 275, 82-177 (2004).

3. Janardhanan, R., Karuppaiah, M., Hebalkar, N. and Rao, T. N., Synthesis and surface chemistry of nano silver particles. Polyhedron 28(12), 2522-2530 (2009). 
4. Chitra, K. and Annadurai, G., Antimicrobial activity of wet chemically engineered spherical shaped ZnO nanoparticles on food borne pathogen. IFRJ, 20(1), 59-64 (2013).

5. Klingshirn, ZnO: material, physics and applications. Chem. PhyChem. 8, 782-803. (2007).

6. Yamamoto, O., Influence of particle size on the antibacterial activity of zinc oxide. Int. J. Inorg. Mater. 3(7), 643-646 (2001).

7. Azam, A., Ahmed, A. S. and Oves, M., Antimicrobial activity of metal oxide nanoparticles against Gram-positive and Gram-negative bacteria: a comparative study. Int. J. Nanomedicine 7, 6003-6009 (2012).

8. Jones, N., Ray, B., Ranjit, K. T. and Manna, A. C., Antibacterial activity of ZnO nanoparticle suspensions on a broad spectrum of microorganisms. FEMS Microbiol. Lett. 279, 71-76 (2008).

9. Fang J., Zhong C. and Mu, R., The study of deposited silver particulate films by simple method for efficient SERS. Chem. Phys. Lett. 401, 271-275 (2005).

10. Kaya, E.G., Özbİlge H. and Albayrak, S., Determination of the effect of Gentamicin against Staphylococcus aureus by using microbroth kinetic system. Ankem Dern, Association of Antibiotics and Chemotherapy, Turkish, 23(3), 110-114 (2009).

11. Kumar, S.S., Venkateswarlu, P., Rao, V.R. and Rao, G.N., Synthesis, characterization and optical properties of zinc oxide nanoparticles. Int. Nano Lett. 3(1), 30 (2013)

12. Lanje A.S., Sharma, S.J., Ningthoujam, R.S., Ahn, J.-S. and Pode, R.B., Low temperature dielectric studies of zinc oxide $(\mathrm{ZnO})$ nanoparticles prepared by precipitation method. Adv. Powder Technol. 24(1), 331-335 (2013).

13. Chauhan, R. and Kumar, A., Photocatalytic studies of silver doped $\mathrm{ZnO}$ nanoparticles synthesized by chemical precipitation method. J. Sol-Gel Sci. Technol. 63, 546-553 (2012).

14. Brause, R., Möltgen, H. and Kleinermanns, K., Characterization of laser-ablated and chemically reduced silver colloids in aqueous solution by UV/VIS spectroscopy and STM/SEM microscopy. Appl. Phys. B Lasers Opt. 75(6-7), 711-716 (2002).

15. Sosa, I.O., Noguez, C., Barrera, R.G., Sosa, I.O., Noguez, C. and Barrera, R.G., Optical properties of metal nanoparticles with arbitrary shapes. J. Phys. Chem. B 107 (26), 6269-6275 (2003).

16. Mandal, S., Selvakannan, P.R., Pasricha, R. and Sastry, M., Keggin ions as UVswitchable reducing agents in the synthesis of Au core-Ag shell nanoparticles. J. Am. Chem. Soc. 125(28), 8440-8441 (2003).

17. Das, R., Preparation and antibacterial activity of silver nanoparticles. J. Biomaterials and Nanobiotechnol. 2(4), 472-475 (2011).

Egypt. J. Biophys. Biomed. Engng. Vol. 17(2016) 
18. Shah, A. H., Manikandan, A., Ahmed, M. B. and Ganesan, V., Enhanced bioactivity of $\mathrm{Ag} / \mathrm{ZnO}$ nanorods-A comparative antibacterial study (Sbds). $J$. Nanomedicine and Nanotechnol. 4(4), 168-173 (2013).

19. Yousef, M. J. and N. Danial, E., In vitro antibacterial activity and minimum inhibitory concentration of zinc oxide and nano-particle zinc oxide against pathogenic strains. $J$. Health Sci. 2(4), 38-42 (2012).

20. Zvekić, D., Srdić, V.V., Karaman, M. A. and Matavulj, M.N., Antimicrobial properties of $\mathrm{ZnO}$ nanoparticles incorporated in polyurethane varnish. Process. Appl. Ceram. 5(1), 41-45 (2011).

21. Wang, Chao, Lian -Long Liu, Ai-Ting Zhang, Peng Xie, Jian-Jun Lu and XiadTing Zou, Antibacterial effects of zinc oxide nanoparticles on Escherichia coli K88. African J. Biotechnol. 11(44), 10248-10254 (2012).

22. Shailaja, D., Shailaja, M., Roselin, P. M. J. and Shalin, N., Comparative studies of synthesis, stability and antibacterial activity of zinc oxide nano-particles. Int. J. Bioassays 914-917 (2013).

23. Shahverdi, A.R., Fakhimi, A., Shahverdi, H.R. and Minaian, Sara, Synthesis and effect of silver nanoparticles on the antibacterial activity of different antibiotics against Staphylococcus aureus and Escherichia coli. Nanomedicine Nanotechnology, Biol. Med. 3(2), 168-171 (2007).

24. Li Wen Ru, Xiao Bao Xie, Qing Shan Shie, Hai Yan Zeng, You Sheng Ou-Yang and Yi Ben Cehn, Antibacterial activity and mechanism of silver nanoparticles on Escherichia coli. Appl. Microbiol. Biotechnol. 85(4), 1115-1122 (2010).

25. Kim, J. S., Kuk, E., Yu, K. N., Kim, J. H., Park, S. J., Lee, H. J. and Kim, et al., Antimicrobial effects of silver nanoparticles. Nanomed. Nanotechnol. Biol. Med. 3(1), 95-101 (2007).

26. Li, M., Zhu, L. and Lin, D., Toxicity of $\mathrm{ZnO}$ nanoparticles to Escherichia coli : Mechanism and the influence of medium components. Environ. Sci. Technol. 45, 1977-1983 (2011).

27. Rai, M., Yadav, A. and Gade, A., Silver nanoparticles as a new generation of antimicrobials. Biotechnol. Adv. 27(1), 76-83 (2009).

28. Pelgrift, R.Y. and Friedman, A.J., Nanotechnology as a therapeutic tool to combat microbial resistance. Adv. Drug Deliv. Rev. 65 (13-14), 1803-1815 (2013).

(Received 8/3 /2015;

accepted $18 / 10 / 2016)$ 


\section{التأثيرات المضادة للميكروبات لكلا من الجسيمات النانومترية من}

\section{الفضة وأكسيد الزنتك المبات}

محمد إسماعيل الجوهرى ، ثناء إبراهيم شلبي " و سعد يحيى مجاهد

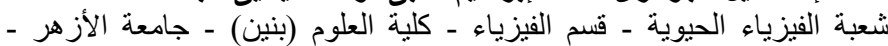

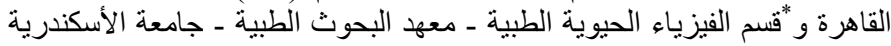

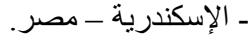

تكنولوجيا النانو تداخلت فى الأونة الأخيرة مع مختلف التخصصات ولطيات ومنها

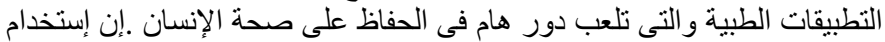

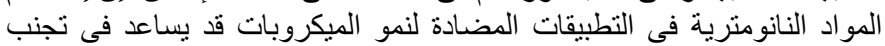

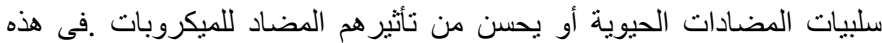

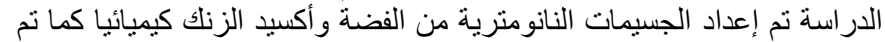

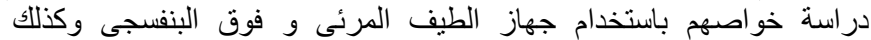

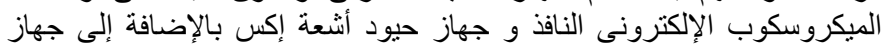

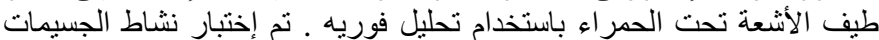

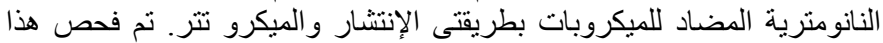

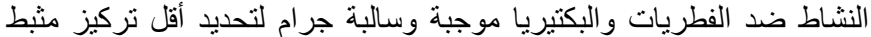

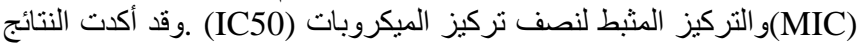

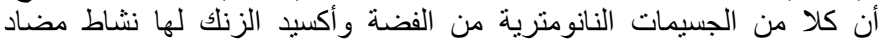

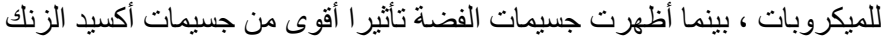

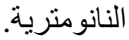

